\title{
THEORETICAL CONSIDERATIONS TO DESIGN LEARNER- GENERATED DIGITAL MEDIA (LGDM) ASSIGNMENTS IN HIGHER EDUCATION
}

\author{
J. Reyna ${ }^{1}$, J. Hanham², P. Meier ${ }^{1}$ \\ ${ }^{1}$ University of Technology Sydney (AUSTRALIA) \\ ${ }^{2}$ Western Sydney University (AUSTRALIA) \\ jorge.reyna@uts.edu.au
}

\begin{abstract}
Digital media as a pedagogical vehicle of learning is becoming common in tertiary educational settings. Students are becoming co-creator rather than passive consumers of content. Most of the research in the field Learner-Generated Digital Media (LGDM) focus on learning course content and neglect the importance of effective communication in the digital space. Students outside media and design courses are not trained on how to create digital media. This paper discusses four different frameworks to use digital media with a dual purpose: learning the subject content and up skill students in the development of digital media literacies.
\end{abstract}

The initial model is the Digital Media Literacy Framework (DMLF) that considers three domains: (i) conceptual, (ii) functional, and (iii) audiovisual. The conceptual domain is related to the identification of suitable content and storyboard production. In contrast, the functional domain includes the technical skills (software and applications) students require for digital media content creation. The audiovisual domain represents the digital media principles that ensure the adequate production of digital media.

The second model is the Taxonomy of Digital Media Types for Learner-Generated Digital Media (LGDM) assignments. The taxonomy map required skills in each of the domains previously discussed and link them with the different types of digital media artefacts.

The third model addresses the core digital media principles at a prosumer level to secure the efficient production of digital media. Principles include layout design, colour theory, typography, use of images and basic video principles.

Finally, the last model, the LGDM framework considers eight steps that are crucial for the implementation of digital media assignment. These steps include: (i) pedagogy, (ii) student training, (iii) hosting of content, (iv) marking rubric, (v) group contribution, (vi) student feedback, (vii) reflection, and (viii) evaluation.

From the educator perspective, these frameworks will support them in the implementation of digital media assignments. From the student perspective, the models can inform the rationale behind for using digital media for learning. Additionally, the models can identify training needs to communicate effectively in the digital space. Implications for teaching and learning are discussed.

Keywords: Digital media for learning, learner-generated digital media, students as co-creators of content, new media literacies, digital media literacies.

\section{Cite as:}

Reyna, J (2018). Theoretical Considerations to Design Learner-Generated Digital Media (LGDM) Assignments in Higher Education. Rethinking Learning in a Connected Age. The 12th annual International Technology, Education and Development Conference, INTED2018, Valencia (Spain), March 5th-7th.

Full paper has been accepted and it will be available online at INTED 2018 Proceedings. 